REVISTA EVIDENCIAÇÃO CONTÁBIL \& FINANÇAS

RECFin

João Pessoa, v. 8, n. 1, p. 130 -150, Jan./Abril. 2020. ISSN 2318-1001

DOI: 10.22478/ufpb.2318-1001.2020v8n1.49750

Disponível em: http://periodicos.ufpb.br/ojs2/index.php/recfin

\title{
DESEMPENHO ECONÔMICO-FINANCEIRO E VINCULAÇÕES POLÍTICAS: TRAÇOS DO PATRIMONIALISMO NAS EMPRESAS DO SETOR ELÉTRICO ESTATAL BRASILEIRO ${ }^{1}$
}

\author{
ECONOMIC-FINANCIAL PERFORMANCE AND POLITICAL FILIATIONS: SIGNS OF \\ PATRIMONIALISM IN BRAZILIAN ELECTRICAL SECTOR STATE COMPANIES
}

\author{
Andréa de Oliveira Gonçalves \\ Doutorado em Integracão da América Latina (USP) \\ Universidade de Brasília \\ andreagon@unb.br \\ Eliedna de Sousa Barbosa \\ Doutorado em Ciências Contábeis (UnB) \\ Universidade Estadual da Paraíba \\ eliedna.barbosa@gmail.com \\ Nara Cristina Ferreira Mendes \\ Doutorado em Ciências Contábeis (UnB) \\ Universidade de Brasília \\ naracfm@gmail.com \\ José Matias-Pereira \\ Doutorado em Ciências Políticas (Universidade Complutense de Madrid) \\ Universidade de Brasília \\ matiaspereira51@gmail.com
}

\section{RESUMO}

Objetivo: Comparar, por ciclos políticos, os segmentos do Grupo Eletrobrás em relação à vinculação político-partidária dos Dirigentes de Alto Nível (DAN) e o desempenho dos indicadores econômico-financeiros, de 2008 a 2014, a fim de verificar a existência de traços do patrimonialismo de Weber.

Fundamento: O modelo de gestão patrimonialista caracteriza-se pelo uso e apropriação do que é público, por dirigentes de partidos políticos e elites dominantes que buscam vantagens para usufruto particular ou corporativo, por meio do predomínio de seus interesses. Sendo essa a base de discussão que permeia esse estudo.

Método: Através do teste de Wilcoxon e Cluster Analysis analisaram-se os indicadores de endividamento oneroso, liquidez corrente, retorno sobre o ativo total e os cargos de Direção e Assessoramento Superiores (5 e 6) do Grupo Eletrobrás, denominados DAN, que representam os mais al-

\footnotetext{
${ }^{1}$ Artigo recebido em: 12/12/2019. Revisado por pares em: 26/12/2019. Recomendado para publicação: 02/01/2020 por Lidiane Nazaré da Silva Dias (Editora Adjunta). Publicado em: 01/05/2020. Organização responsável pelo periódico: UFPB
} 
tos da hierarquia administrativa no setor público no Brasil, ocupados por livre nomeação. Disponíveis no Sistema de Informações Estatais no Tribunal Superior Eleitoral e nos Relatórios da Administração.

Resultados: Não ocorreram diferenças estatisticamente significativas entre os ciclos políticos. Observou-se endividamento elevado, liquidez corrente baixa e o retorno esperado do ativo negativo. Na vinculação político-partidária $68 \%$ dos DAN são filiados e/ou doadores ao partido da base dos ciclos analisados, apontando indícios de heranças patrimonialistas de Weber.

Contribuições: Discute-se a interferência do viés político nos cargos dos DAN, diante da discricionariedade da nomeação, do alto grau de poder de decisão delegado e da possibilidade de atuarem em prol de grupos de interesses privados em detrimento do interesse da sociedade.

Palavras chave: Indicadores Econômico-financeiros Patrimonialismo; Vinculação Política; Setor Elétrico Estatal Brasileiro.

\section{ABSTRACT}

Objective: to compare, by political cycles, the segments of the Eletrobrás Group relative to the political party-filiation of the High Level Directors (HLD) and the performance of economic-financial indicators, from 2018 to 2014, in order to verify the presence of patrimonialism as defined by Weber.

Theoretical Grounding: the patrimonialist management model is characterized by the use and appropriation of public goods by political party directors and dominant elites, seeking advantages for individual or corporate benefit, by imposing their interests. This will be the theoretical basis for this study.

Method: The Wilcoxon test and cluster analysis analyzed the onerous indebtedness indicators, current liquidity, return on the total active and was made from the positions of Superior Director and Advisor (5 and 6) of the Eletrobrás group, which represent the highest of the administrative hierarchy in the public sector in Brazil, occupied by free appointment collected from the State Information System website, the Superior Electoral Court and Administration Reports.

Results: There were no statiscally significant differences between political cycles. High indebtedness, low current liquidity and an expected return of the active negative were observed. In political party filiations, $68 \%$ of the HLD were filiated or donors to the base party of the analyzed cycles, indicating signs of Weber's patrimonialist heritage.

Contributions: a relevant lack of literature is discussed, reflecting on the interference of political biases on the HLD positions, considering the arbitrariness of nomination, high degree of delegated decision-making power and the possibility of acting in favor of private interest groups instead of social interests.

Keywords: Economic-financial Indicators; Patrimonialism; Political Party Filiations; Brazilian State Electrical Sector.

\section{INTRODUÇÃO}

A história remete ao estado luso com traços característicos patrimonialistas (Faoro, 2001), onde a "propriedade do rei, suas terras e seus tesouros, se confunde nos seus aspectos público e particular" (Faoro, 2001, p. 23), como responsável por diversos problemas econômicos, políticos e sociais observados que se prolongam no Brasil no século XX e perduram no contemporâneo (Faoro, 2012). Semelhante a Faoro, para Holanda (1995) a família patriarcal se consolida nas relações 
sociais do Brasil, onde a vida política nacional invade a esfera privada, e "fornece, assim, o grande modelo por onde se hão de calcar, as relações entre governantes e governados, entre monarcas e súditos" (Holanda, 1995, p. 85).

Por sua vez, a administração pública patrimonial é uma forma do exercício de dominação por uma autoridade, a qual está legitimada tradicionalmente, cujas características repousam no poder individual do governante, que exerce o poder político sob um determinado território, que caracteriza-se por um quadro administrativo composto de companheiros ou súditos, recrutados por critérios de afetividade, lealdade e confiança. Esse estamento aristocrático, vai se burocratizando de forma progressiva, em uma mudança de acomodação e não estrutural, se apropriando do Estado, de seus cargos e funções públicas, impondo um regime de uso das vantagens advindas da máquina estatal, para a satisfação de interesses particulares (Rocha Neto, 2008; Costa, 2012; Faoro, 2012).

A categoria patrimonialismo, aqui apresentada como um modo de dominação tradicional, na sociologia política de Weber (2000), delimita-se no grau de controle dos governantes sobre os instrumentos de gestão do poder (modelo dual-estrutural), ou seja, no enfoque institucionalorganizacional. Nesse sentido, contribuições de Faoro (1979, 2001, 2012), Holanda (1976), Franco (1976) e Carvalho (1980) são fundamentais para a compreensão do fenômeno descrito inicialmente por Max Weber. Segundo Lamounier (2014) longe de esgotar sua força persuasiva, o patrimonialismo encontra-se no centro do debate político sobre o papel do Estado.

Estudos sobre as elites políticas que enfatizam as redes de relacionamento e à atuação política são crescentes (Palotti, \& Cavalvante, 2018). Variáveis socioeconômicas apontam para o pertencimento dessas elites a estratos específicos da sociedade (Carvalho, 2009). Para Corrêa (2010) no Brasil os governos são caracterizados por serem de "coalizão". Segundo Inácio (2013) que estudou os padrões de escolhas dos partidos políticos para nomeação de ministros, as nomeações são elementos importantes para ampliar a competitividade do partido por meio da expansão vertical e horizontal da organização partidária.

Com recorte mais específico, D'Araújo (2009), propôs conhecer em detalhes os ocupantes dos cargos de Direção e Assessoramento Superiores (DAS), níveis 5 e 6, dos cargos de Natureza Especial (NES), dos ministros, dirigentes de fundos de pensão e grupo de pessoas que chegaram ao topo da administração pública federal, no âmbito do Poder Executivo, no período de 2003 a 2010. O que resultou em descrever a formação acadêmica, as carreiras profissionais e os vínculos associativos e políticos dessa elite dirigente, que Faoro (1979) profere de estamento burocrático.

Dentro desse contexto, o presente estudo partiu dos cargos de DAS como ponto de investigação, lacuna de pesquisa na área contábil, para buscar responder como traços do patrimonialismo pode ser verificado em relação a vinculação político-partidária dos dirigentes de alto nível e os indicadores econômico-financeiros do setor elétrico estatal brasileiro? Nesse sentido, objetiva-se comparar os segmentos do Grupo Eletrobrás em relação à vinculação político-partidária de dirigentes de alto nível e ao desempenho dos indicadores econômico-financeiros, por ciclos políticos, de 2008 a 2014, a fim de verificar a existência de traços do patrimonialismo weberiano.

Assim, esse estudo busca mudar a lente de observação ao adentrar em empresas estatais, a fim de contribuir promovendo discussão e reflexão acerca de traços do patrimonialismo weberiano, por meio da interferência de conveniências político-partidárias nos cargos de DAS (5 e 6). Diante da discricionariedade da nomeação e do alto grau de poder de decisão delegado, estes podem atuar em prol de grupos de interesses em detrimento do interesse da sociedade. Cabe ressaltar, que nesse caso mesmo tratando-se de ciclos políticos de mesma base partidária, não há prejuízo na análise, pois os indicadores econômico-financeiros são tidos como dimensionadores de desempenho de gestão, independente de mudanças dos partidos do poder político. E, eles são uma das possibilidades de sinalização de práticas que Weber (2000) enfatiza como sendo a relação de domina- 
ção (Herrschaft) que representa a probabilidade de encontrar obediência para ordens seja específica ou total dentro de determinado grupo de pessoas.

Dessa forma, o presente estudo estrutura-se em cinco seções: a primeira seção volta-se à introdução do estudo; a segunda expõe o referencial teórico do tema proposto; a terceira se refere à metodologia utilizada; a quarta seção trata dos resultados da pesquisa; e, a quinta contém as considerações finais, seguida das referências utilizadas.

\section{REFERENCIAL TEÓRICO}

\subsection{O Patrimonialismo de Max Weber}

Max Weber, um dos pensadores clássicos das Ciências Sociais, principal referência na literatura sobre o termo "patrimonialismo" que surge no fim do século XIX definindo tipologias das formas de dominação, expõe sua formulação canônica do conceito de dominação patrimonial, no livro Economia e Sociedade, sustentada a partir de diferentes naturezas de legitimidade ocasionadas por associações de dominação (Weber, 2000).

Segundo Weber (2000) são três os tipos de dominação: i) a legal, que é de caráter racional, baseada na crença na legitimidade das ordens estatuídas e do direito de mando daqueles que, em virtude dessas ordens, estão nomeados para exercer a dominação; ii) a tradicional, que é baseada na crença cotidiana na santidade das tradições vigentes desde sempre e na legitimidade daqueles que, em virtude dessas tradições, representam a autoridade; e, iii) a carismática que é baseada na veneração extra cotidiana da santidade, do poder heroico ou do caráter exemplar de uma pessoa e das ordens por esta reveladas ou criadas.

Do tipo de dominação tradicional Weber (2000) chega ao conceito de patrimonialismo como sendo toda dominação que, originariamente, inspirada pela tradição, é exercida em virtude de um direito pessoal. Portanto, esse é o foco do presente estudo.

Logo, o patrimonialismo se revela sobre duas formas de dominação tradicional, as que não possuem quadro administrativo e as que o possuem. As que não possuem quadro administrativo de acordo com Portela Jr. (2012) são conhecidas como a "gerontocracia" (quando exercida pelos mais velhos, por estes possuírem maior conhecimento sobre a tradição) e o "patriarcalismo" (quando a dominação é exercida por direito hereditário, por sucessão).

Weber apresenta diferentes perspectivas sobre como interpretar a atividade da política e dos políticos profissionais na luta pelo poder, possibilita pela ocasião, oportunidade ou situação de fazer algo para algum propósito específico (Palonen, 2019).

É diante deste cenário que surge o quadro administrativo e onde a dominação tradicional tende ao patrimonialismo. As funções e serviços executados pelo quadro administrativo, no âmbito da organização, são primeiramente sujeitas aos comandos do senhor, representando um estereótipo em função da tradição. Para Weber (2004b, p.193) "toda dominação manifesta-se e funciona como administração. Toda administração precisa, de alguma forma, da dominação, pois para dirigi-la, é mister que certos poderes de mando se encontrem nas mãos de alguém".

Contudo, na dominação patrimonial, as normas e os regulamentos burocráticos não são considerados, o funcionário patrimonial se distingue do funcionário burocrata, pois no primeiro a relação é pessoal (fidelidade) e de submissão ao senhor e no segundo a relação é de fidelidade de servidor ao desenvolver tarefas objetivas mediante regras racionalmente estabelecidas (Weber, 2004).

Assim, "o cargo e o exercício do poder público estão a serviço da pessoa do senhor, por um lado, e do funcionário agraciado com o cargo, por outro, e não de tarefas objetivas" (Weber, 2004a, p. 255). 
Diante do exposto, cabe frisar que no tipo puro de funcionalismo patrimonial a seleção do quadro ocorre mediante qualificações puramente pessoais. Portanto, a administração patrimonial se fundamenta tanto no poder político, organizado por meio do poder arbitrário e legitimado pela tradição, como nos elementos culturais da própria sociedade, onde não há a distinção entre esfera privada e a pública. Fica claro que é tratada como assunto pessoal do governante e o patrimônio público como parte de sua propriedade.

E, como traços da ineficiência governamental no patrimonialismo destacam-se: a personalização do poder, a racionalidade subjetiva do sistema jurídico, a falta de profissionalização do quadro administrativo, e, a tendência intrínseca à corrupção do quadro administrativo como questão cultural (Campante, 2003).

\subsection{O Patrimonialismo no Brasil}

Limita-se às contribuições desenvolvidas pelos autores Raymundo Faoro, Sérgio Buarque de Holanda e José Murilo de Carvalho, voltados ao estudo da ausência de racionalidade, formalismo e legalidade da distribuição e forma de execução dos cargos públicos.

De acordo com Costa (2012) com base nas raízes do povo brasileiro, na tentativa de conhecer o que envolve a relação histórica entre a sociedade e o Estado, esses autores encontram no patrimonialismo recorrente, a feição de personalismo, favoritismo, clientelismo, entre outros, uma das vicissitudes que explicam o atraso do país em termos de desenvolvimento, modernização e competitividade.

Na obra mais importante de Faoro (Os Donos do Poder), lançada em sua primeira edição em 1958, a tese central é a de que na formação sócio-político brasileira há a permanência de um patrimonialismo estamental. Segundo Weber (2002) estamento é o conjunto de homens que aspiram a um tratamento social exclusivo ou a um monopólio exclusivo de caráter estamental.

Faoro (2001) tomando por base Weber caracterizou na formação nacional brasileira a existência de um poder central muito forte que inibiu qualquer formação social espontânea e que determinou todas as mudanças sociais de "cima para baixo". Neste sentido, o estamento é tido como algo permanente na história brasileira e alvo de severas críticas. Para Faoro (2001, p. 104) “o governo, o efetivo comando da sociedade, não se determina pela maioria, mas pela minoria que a pretexto de representar o povo, o controla, o deturpa, o sufoca".

Por sua vez, Holanda (1976) explica que, à medida que ocorre a racionalização e uma progressiva divisão de funções, o funcionalismo patrimonial pode apresentar traços burocráticos, mas em sua essência continua diferindo do funcionalismo burocrático, principalmente, quando se caracteriza com mais profundidade os dois tipos. Para os empregos e funções públicas costuma prevalecer a confiança pessoal que mereçam os candidatos dos seus padrinhos, e muito menos as suas qualificações próprias. No Estado brasileiro, desde sua origem, falta a ordenação impessoal que caracteriza a vida no Estado burocrático.

Logo, o modelo de gestão patrimonialista caracteriza-se, fundamentalmente, pelo uso e apropriação do que é público, inclusive do aparelho do Estado e do próprio Estado por dirigentes de partidos políticos e elites dominantes que buscam vantagens para usufruto particular ou corporativo, por meio do predomínio de seus interesses através de benefícios e favorecimentos concedidos pelo poder público. Sendo essa a base de discussão que permeia esse estudo.

\subsection{Os Indicadores de Desempenho Econômico-Financeiro}

A aplicação de sistemas de indicadores de desempenho é de fundamental importância para tomada de decisão. Muitos deles são definidos internamente às próprias empresas, mas outros para serem calculados exigem dados e informações externas. Para Kaplan \& Norton (1997) medir desempenho é importante e os indicadores são utilizados pelas empresas que quiserem sobreviver 
e prosperar. Corrobora Campbell (1997) que nem todas as medidas de desempenho que são necessárias são encontradas nos tradicionais relatórios financeiros.

Os indicadores, também, são essenciais para o planejamento e o controle dos processos das organizações, possibilitando o estabelecimento de metas fundamentais para a análise crítica dos desempenhos e para recomeçar ciclos de planejamento. Aras \& Crowther (2009) argumentam que a mensuração e a evidenciação dos indicadores são imprescindíveis para a avaliação e o monitoramento das ações sustentáveis da empresa pela sociedade.

A análise de balanços por meio da criação de índices facilita o processo de tomada de decisões de investimento, financiamento e operacionais, uma vez que fornece informações sobre a eficiência das operações da empresa e sua situação econômico-financeira (Nava, 2009). Assaf Neto (2012) apresenta dezessete índices a serem calculados e que são classificados em três grandes grupos, a saber, o grupo de Capital e Risco, o grupo Rentabilidade e Lucratividade, e o grupo Solvência e Liquidez.

Para realizar análise econômico-financeira é possível utilizar, entre outros índices, o de liquidez, o de endividamento e o de rentabilidade. No entanto, a apreciação deles não se trata exclusivamente da aplicação de uma operação isolada, a interpretação e a capacidade de concluir se o indicador é positivo ou negativo em determinada circunstância é um aspecto fundamental no processo de avaliação (Gitman, 2010).

Desta forma, para analisar os índices econômico-financeiros por segmento do Grupo Eletrobrás, limitou-se aos disponíveis no Sistema de Informações Estatais (SIEST): o Indicador de Endividamento Oneroso (ID EO); o Indicador de Desempenho Liquidez Corrente (ID LC) e, o Indicador de Desempenho Retorno sobre o Ativo Total (ID ROA), descritos na Tabela 1.

Tabela 1 - Indicadores de Desempenho Econômico-Financeiro

\begin{tabular}{l|l}
\hline \multicolumn{1}{c|}{ Indicadores } & \multicolumn{1}{c}{ Descrição } \\
\hline $\begin{array}{l}\text { Indicador de Endividamento One- } \\
\text { roso (ID EO) }\end{array}$ & $\begin{array}{l}\text { Demonstra o tamanho da dívida da empresa, assim como a qualidade } \\
\text { da dívida e mede o grau de alavancagem da empresa que é utilizado } \\
\text { para compor a sua estrutura de capital (Póvoa, 2010). }\end{array}$ \\
\hline $\begin{array}{l}\text { Indicador de Desempenho Liquidez } \\
\text { Corrente (ID LC) }\end{array}$ & $\begin{array}{l}\text { Demonstra a capacidade que uma empresa tem para honrar seus com- } \\
\text { promissos no curto prazo sem maiores preocupações. Consequente- } \\
\text { mente, se concentram nos ativos e passivos circulantes (Ross, Westerfi- } \\
\text { eld, Jordan, \& Lamb, 2013). }\end{array}$ \\
\hline $\begin{array}{l}\text { Indicador de Desempenho Retorno } \\
\text { sobre o Ativo Total (ID ROA) }\end{array}$ & $\begin{array}{l}\text { Mede quão bem os ativos de uma empresa foram empregados pela } \\
\text { gerência (Garrison, Noreen, \& Brewer, 2013). }\end{array}$ \\
\hline
\end{tabular}

Fonte: Elaborado pelos autores.

Assim, é possível realizar comparações, estabelecer relações que não são evidentes num simples olhar dos números apresentados nas demonstrações contábeis, possibilitando conhecer a posição da empresa, analisar eventos passados e projetar tendências em cenários futuros.

\subsection{Regulação do Setor Elétrico no Brasil}

Na década de 1970 surge a Teoria da Regulação, a partir de trabalhos de economistas políticos franceses, no âmbito da Escola Francesa de Regulação, visa substituir a teoria do equilíbrio econômico geral e analisar o impacto das relações sociais sobre a regularidade econômica (Boyer, 1990).

Na ciência política, regulação é sinônimo de ordem, equilíbrio, diante de uma fundamentação na função normativa. Essa noção assegura a integração contínua de grupos, como condição de existência na sociedade global (Miaille, 1995). Para Gaudin (1995) o poder político regula a sociedade, ao buscar por interesses opostos e estratégias contrárias ao almejado pela sociedade. 
No âmbito da teoria econômica a regulação possui relação com a existência de falhas de mercado e consiste na imposição de regras e controles pelo Estado. Para Silva (2002/2003), as falhas de mercado ocorrem: diante de diferentes estruturas de mercado (monopólio, oligopólio, concorrência monopolista e concorrência perfeita); existência de externalidades e assimetria de informação; existência de bens públicos (bem caracterizados como não rivais e não excludente); e, nos casos de monopólios naturais.

Nos casos de monopólios ou mercados com estruturas produtivas partilhadas, a intervenção do Estado, por meio da regulação, deve ocorrer no intuito de garantir o alcance da eficiência (Ramalho, 2009). Ressalta-se, que os serviços de utilidade pública como transmissão e distribuição de energia elétrica, fornecimento de água, sistema de esgotos, dentre outros, estão propícios à formação de monopólios naturais diante da inexistencia de substitutos perfeitos (Basso \& Silva, 2000).

A regulação pode ser classificada em três categorias: um conjunto de regras imperativas executadas por uma agência estatal, como esforços desenvolvidos para orientar a economia e como mecanismo de controle social. Em casos onde o mercado não é controlado, ocorre a falha no atendimento do interesse público, justificando a necessidade de regulação econômica (Baldwin \& Cave, 1999). Ela não se restringe ao estímulo da concorrência pois possui por objetivo melhorar o nível de eficiência econômica dos mercados em suas dimensões distributiva, alocativa e produtiva (Possas, Pondé, \& Fagundes, 1997).

Os princípios da regulação exigem preocupação com os monopólios naturais, assim, os órgãos reguladores não devem instituir políticas setoriais independentes e autônomas para que a regulação dos segmentos do mercado e serviços públicos, preservem a livre escolha, prestação de serviços e preços razoáveis à sociedade (Souto, 1999).

As agências regulatórias independentes possuem três características básicas: poder regulador definido por Lei; autonomia administrativa; e autonomia financeira. Elas seriam responsáveis por configurar alto grau de credibilidade à política regulatória, uma vez que diante da referida autonomia as agências estariam ilesas de influências relacionadas ao jogo político tradicional (Montone, 2010).

O setor elétrico brasileiro é regulado pela Agência Nacional de Energia Elétrica, constituída por meio da Lei n⿳0 9.427/96 e do Decreto n⿳0 2.335/97, com a missão de proporcionar condições favoráveis para que o mercado de energia elétrica se desenvolva com equilíbrio entre os agentes e em benefício da sociedade (ANEEL, 2018).

Ressalta-se, que as agências e as empresas estatais, apresentam falhas que pode ensejar na ineficiência das políticas públicas regulatórias por meio da captura por grupos de interesse, atuação norteada por objetivos difusos e baixo grau de coordenação entre reguladores. O fortalecimento do Estado regulador pode advir com a mudança do próprio modelo de governança (Majone, 1999).

Dessa forma, a regulação é vista como função essencial do poder político. Assim, analisar as políticas públicas pode auxiliar na identificação da negociação e da agregação de conflitos entre a sociedade e seus representantes.

\subsection{Os Cargos no Brasil de Direção e Assessoramento Superiores}

Os Cargos de Direção e Assessoramento Superior (DAS) são cargos em comissão de livre nomeação e exoneração, onde os agentes que os ocupam possuem as atribuições de direção, chefia e assessoramento nas empresas públicas ou sociedades de economia mista, conforme previsto na Constituição Federal em seu artigo 37. Qualquer cidadão pode ser livremente nomeado a ocupá-lo e atuar como agente público, sem concurso, nos altos cargos da hierarquia administrativa pública, conhecidos como Dirigentes de Alto Nível (DAN). 
Constituídos por meio do Decreto-Lei no 200 de 25 de fevereiro de 1967, com fins de aperfeiçoar a máquina pública, se classificam em seis níveis hierárquicos, no âmbito do Poder Executivo, regulamentada pelo Decreto no 6.944, de 21 de agosto de 2009, e pelo Decreto o 8.886, de 24 de outubro de 2016, sendo a descrição por nível apresentada conforme Tabela 2.

Tabela 2 - Descrição dos cargos de DAS

\begin{tabular}{l|l}
\hline \multicolumn{1}{c|}{ CÓDIGO DAS } & \multicolumn{1}{c}{ DESCRIÇÃO } \\
\hline DAS 101.6 & $\begin{array}{l}\text { Secretário de área finalística, secretário-executivo adjunto, presidente de autarquia e fun- } \\
\text { dação, subsecretário de órgão da Presidência da República, ouvidor-geral da União, corre- } \\
\text { gedor-geral da União. }\end{array}$ \\
\hline DAS 101.5 & $\begin{array}{l}\text { Chefe de gabinete de Ministro de Estado, diretor de departamento ou diretoria, diretor de } \\
\text { programa, consultor jurídico, secretário de controle interno, subsecretário de ministério, } \\
\text { procurador-chefe de procuradoria federal especializada, secretário-adjunto, chefe de asses- } \\
\text { soria especial. }\end{array}$ \\
\hline DAS 101.4 & $\begin{array}{l}\text { Chefe de gabinete de secretário, coordenador-geral, chefe de gabinete de autarquias e de } \\
\text { fundações, chefe de assessoria, auditor chefe, auditor-interno, diretor-adjunto, procurador- } \\
\text { chefe de procuradoria federal, gerente de projeto, corregedor, ouvidor, superintendente- } \\
\text { geral, gerente regional, superintendente-regional, superintendente estadual. }\end{array}$ \\
\hline DAS 101.3 & Coordenador, superintendente, delegado. \\
\hline DAS 101.2 & Chefe de divisão. \\
\hline DAS 101.1 & $\begin{array}{l}\text { Chefe de serviço, chefe de centro, chefe de distrito; DAS 102.6, assessor especial da Presi- } \\
\text { dência da República. }\end{array}$ \\
\hline
\end{tabular}

Nota. Fonte: Com base no Decreto n⿳o 6.944/ 2009 e no Decreto $n^{\circ}$ 8.886/2016.

DAS 101.1 é o cargo hierarquicamente inferior enquanto o DAS 101.6 possui o maior poder de decisão, sendo o de nível superior. Os DAS de nível 5 e 6 estão subordinados aos ministros e secretários-executivos, bem como desempenham funções estratégicas no Governo. D'Araujo (2009) destaca que a estrutura dos DAS pouco se alterou desde a sua constituição.

A Lei n⿳⺈ 13.303/2016, denominada Lei das Estatais ou Lei de Responsabilidade das Estatais (LRE), com o objetivo de regulamentar o art. 173, § 1ํ da Constituição Federal de 1988, sobre diversos aspectos relacionados às empresas públicas e sociedades de economia mista no âmbito da União, Estados, Municípios e Distrito Federal, enfatizou a preocupação em tornar mais rigorosa a questão de indicação dos dirigentes das estatais.

De fato, é inegável que a referida Lei cobre importante lacuna normativa, desde 1988. Contudo, mesmo diante dos novos parâmetros para dirigentes de alto nível nas estatais, as indicações políticas, que favorece um sistema de trocas de interesses, levando a um aparelhamento político, aumentando a probabilidade de beneficiamento de esquemas entre empresas e políticos, envolvendo inclusive apoio e/ou financiamento de candidaturas e compra de votos, ainda, faz parte do cenário brasileiro. O controle dos DAN das estatais apresenta desafios a superar para garantir a eficiente prestação dos serviços.

O presente estudo aborda os cargos de DAS de níveis 5 e 6, diante da discricionariedade em sua nomeação, do alto grau de poder de decisão delegado e da possibilidade de seus ocupantes serem nomeados por conveniências político-partidárias, estes podem atuar em prol de grupos de interesses privados em detrimento do interesse da sociedade, o que corrobora como traços do patrimonialismo de Weber.

\section{METODOLOGIA}

Neste artigo foi realizada uma pesquisa de caráter exploratório-descritivo, quanti-quali e bibliográfica, tendo como universo de estudo o Grupo Eletrobrás que atua nos segmentos de geração, distribuição, transmissão e comercialização de energia por meio de dezesseis (16) empresas. 
Para analisar a vinculação político-partidária dos Dirigentes de Alto Nível (DAN), optou-se por restringir-se aos equivalentes cargos de Direção e Assessoramento Superiores - DAS 5 e 6, que representam os mais altos cargos da hierarquia administrativa no setor público no Brasil e podem ser ocupados por livre nomeação. Identificou-se quatrocentos e trinta e três (433) DAN ocupantes de cargos públicos, distribuídos na amostra formada por treze (13) empresas (aproximadamente 81\%) do Grupo Eletrobrás, conforme Tabela 3.

Tabela 3 - Apresentação da amostra da pesquisa

\begin{tabular}{|c|c|c|}
\hline EMPRESAS DO GRUPO ELETROBRÁS & SEGMENTOS & $\begin{array}{c}\text { CODIFICAÇÃO } \\
\text { DOS SEGMENTOS }\end{array}$ \\
\hline Centrais Elétricas Brasileiras S.A. (Eletrobrás) & Holding & 1 \\
\hline $\begin{array}{l}\text { Centrais Elétricas do Norte do Brasil S.A. (ELETRO- } \\
\text { NORTE) }\end{array}$ & \multirow{4}{*}{ Geração e Transmissão } & \multirow{4}{*}{2} \\
\hline Companhia Hidro Elétrica do São Francisco (CHESF) & & \\
\hline Furnas - Centrais Elétricas S.A. (FURNAS) & & \\
\hline Eletrosul Centrais Elétricas S.A. (ELETROSUL) & & \\
\hline $\begin{array}{l}\text { Companhia de Geração Térmica de Energia Elétrica } \\
\text { (CGTEE) }\end{array}$ & \multirow[t]{2}{*}{ Geração } & \multirow[t]{2}{*}{3} \\
\hline Eletrobrás Termonuclear S.A. (ELETRONUCLEAR) & & \\
\hline Companhia Energética de Alagoas (CEAL) & \multirow{4}{*}{ Distribuidoras } & \multirow{4}{*}{4} \\
\hline Companhia Energética do Piauí (CEPISA) & & \\
\hline Centrais Elétricas de Rondônia S.A. (CERON) & & \\
\hline Boa Vista Energia S.A. (BVENERGIA) & & \\
\hline Eletrobrás Participações S.A. (ELETROPAR) & Participação Acionária & 5 \\
\hline Centro De Pesquisas De Energia Elétrica (CEPEL). & Centro de Pesquisa & 6 \\
\hline
\end{tabular}

Fonte: Elaborado pelos autores.

A janela temporal de estudo correspondeu a sete (7) exercícios financeiros, entre 2008 a 2014, com exceção do ano de 2007, início do Ciclo 1, por falta da disponibilização dos dados. Logo, o Ciclo 1 refere-se de 2008 a 2010 e o Ciclo 2 de 2011 a 2014.

A identificação e coleta das variáveis ocorreu nos sites oficiais do Sistema de Informações Estatais (SIEST) do Departamento de Coordenação e Governança das Empresas Estatais (DEST) e do Tribunal Superior Eleitoral (TSE). Também, foram consultados os Relatórios da Administração (RA) do Grupo Eletrobrás e de cada uma das empresas apresentadas na Tabela 2 e o Relatório Anual do Perfil das Empresas Estatais Federais. Desse modo, foram selecionadas as variáveis codificadas e apresentadas na Tabela 4. 
Tabela 4 - Variáveis utilizadas na pesquisa

\begin{tabular}{l|l}
\hline CÓDIGOS & \multicolumn{1}{c}{ VARIÁVEIS } \\
\hline & $\begin{array}{l}\text { Indicador de Endividamento Oneroso - mede a participação de empréstimos, financiamentos e } \\
\text { arrendamentos mercantis em relação ao total do passivo, sua interpretação consiste em quanto } \\
\text { maior, maior a despesa financeira, sendo sua fórmula: }\end{array}$ \\
$\begin{array}{l}\text { ID EO } \\
\text { ID EO (\%) }\end{array}$ & $\begin{array}{l}\text { Indicador de Desempenho Liquidez Corrente - indica a capacidade de pagamento da empresa no } \\
\text { curto prazo, sua interpretação consiste em quanto maior, melhor, sendo sua fórmula: }\end{array}$ \\
\hline ID LC & $\begin{array}{l}\text { Passivo Total } \\
\text { Passivo Circulante }\end{array}$ \\
\hline ID ROA & $\begin{array}{l}\text { Indicador de Desempenho Retorno sobre o Ativo Total - indica a rentabilidade das operações da } \\
\text { empresa em relação aos seus ativos médios, sua interpretação consiste em quanto maior, melhor, }\end{array}$ \\
\hline RT & Rendo sua fórmula: \\
\hline DT & Receita Total (Orçamentos de Custeio e Investimentos) \\
\hline DAN & Dirigentes de Alto Nível (DAS 5 e 6) \\
\hline DF & Dirigentes Filiados \\
\hline DC & Dirigentes Candidatos \\
\hline DD & Dirigentes Doadores \\
\hline
\end{tabular}

Fonte: Elaborado pelos autores.

Para as variáveis monetárias, realizou-se o deflacionamento pelo Índice de Preços ao Consumidor Amplo (IPCA), removendo os efeitos da variação de preços, transformando-os em moeda constante de 2015 todo o período longitudinal.

Para comparar os segmentos do Grupo Eletrobrás por ciclo orçamentário, procedeu-se a estatística descritiva e a aplicação de teste não paramétrico de diferença de média para amostras emparelhadas de Wilcoxon, pois além de considerar a direção das diferenças, permitir comparar a magnitude delas (Maroco, 2007). Para Fávero et al. (2009, p. 158), “o teste de Wilcoxon é uma alternativa ao teste $t$ de Student para comparar duas médias populacionais a partir de amostras emparelhadas".

Por fim, foi utilizada a Cluster Analysis (Análise de Cluster) que se trata de uma análise multivariada usada para classificar objetos ou casos em grupos relativamente homogêneos chamados conglomerados que tendem a ser semelhantes entre si, através do método hierárquico, definido o nível de similaridade pela métrica Distância Euclidiana e ligação completa, sendo representado pelo dendograma (Malhotra, 2001; Janert, 2011; Manly, 2008).

\section{APRESENTAÇÃO E DISCUSSÃO DOS RESULTADOS}

\subsection{O Setor Elétrico Estatal Brasileiro}

A Centrais Elétricas Brasileiras S.A. (Eletrobrás) criada em 1962, empresa de economia mista, maior companhia de capital aberto do setor de energia elétrica da América Latina, controlada 
pelo governo brasileiro, atua nos segmentos de geração, distribuição, transmissão e comercialização de energia elétrica, possui ações negociadas nas Bolsas de Valores de São Paulo, de Madri e de Nova Iorque. Cerca de $91 \%$ da sua capacidade instalada é oriunda de fontes com baixa emissão de gases de efeito estufa, o que a faz uma das maiores do mundo em geração de energia limpa e renovável, conforme dados disponibilizados em seu site oficial.

O modelo brasileiro de geração de energia elétrica é predominantemente hidrelétrico. $\mathrm{O}$ segmento de geração é bastante pulverizado com 3.152 empreendimentos gerados, o de transmissão é constituído de uma rede que se espalha por todo o território nacional com a função de levar a energia elétrica das fontes geradoras até as empresas de distribuição. Essas, são as responsáveis por receber a energia em alta tensão do sistema interligado de transmissão, rebaixá-la a níveis comerciais e fazer chegar ao consumidor final (ANEEL, 2018).

Contudo, a intervenção do governo na história desse setor é visualizada por períodos marcados por estabilidade e baixo risco, e, períodos caracterizados por forte turbulência e risco elevado. Na qualidade de estatal dependente o Grupo Eletrobrás recebe recursos da União, oriundos do Orçamento de Investimentos, para cobertura de despesas com pessoal e para custeio em geral. No período em análise, a média anual das Receitas Totais (RT) e Despesas Totais (DT) do Grupo Eletrobrás por segmentos, vinculadas ao orçamento do Ministério de Minas e Energia, correspondeu aos resultados apresentados a Figura 1.

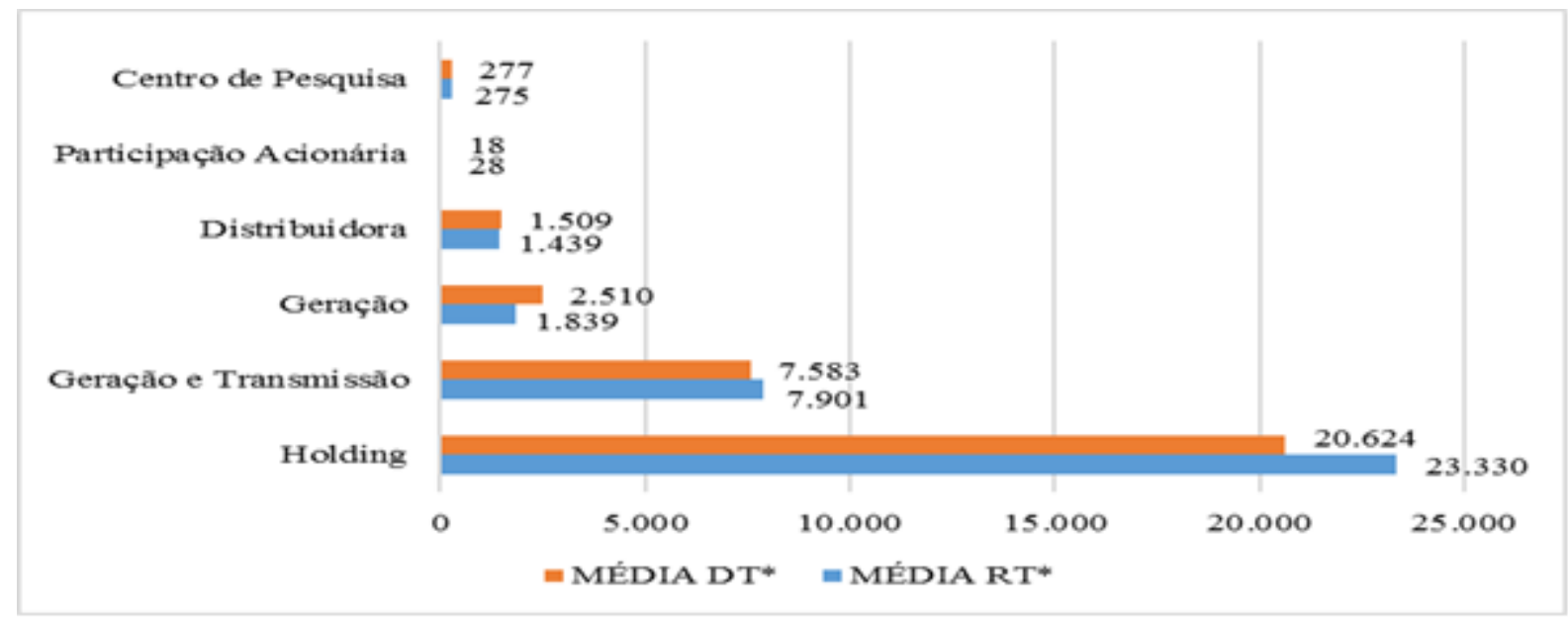

FIGURA 1 - Média anual das RT e DT dos Orçamentos de Investimentos em R\$ (milhar) ${ }^{*} \mathrm{DT}=$ Despesa Total. ${ }^{* *} \mathrm{RT}=$ Receita Total.

Observa-se que as maiores médias/ano foram dos segmentos: Holding e Geração e Transmissão. Já Geração, Distribuidora e Centro de Pesquisa, apresentaram déficit orçamentário, ou seja, DT maiores que RT. A Holding por sua natureza gerencia o maior volume de receitas do grupo Eletrobrás. Contudo, devido à restrição de informações acerca dos orçamentos de investimentos das estatais como um todo no Brasil, não são possíveis análises mais pormenorizadas. Esse é um ponto que chama a atenção para futuras pesquisas.

Cabe, ainda, destacar que a gestão desses orçamentos por segmentos é de competência da Diretoria Executiva formada pela Presidência e pelas demais Diretorias, formada por Dirigentes de Alto Nível (DAS 5 e 6). Segundo D'Araújo (2014) pela posição que esses DAS ocupam em postos de confiança e por seu escopo funcional, logo abaixo dos Ministros, configurariam um espaço gerencial afeito à eficiência e à racionalidade no serviço público.

Mas, sem negar o possível uso político desses cargos no Brasil, eles são suscetíveis de indicações partidárias que compõem a coalizão governamental. Para Olivieri (2007) trata-se de um profissional híbrido, responsável pela eficiência da gestão e pela consecução dos objetivos políticos 
da agenda governamental, sejam políticos, sejam burocratas, são policymakers que devem ser capazes de responder a essa dupla exigência.

\subsection{O TESTE DE WILCOXON}

O teste de Wilcoxon foi utilizado para verificar se a diferença entre as medianas dos scores dos grupos é estatisticamente significativa. Assim, a Tabela 5 apresenta os resultados do referido teste nos Indicadores ID EO (\%), ID LC, ID ROA (\%), de 2008 a 2014, por segmentos do Grupo Eletrobrás, e, a estatística descritiva utilizando as medidas de tendência central, realizada em função da média, da mediana e do desvio-padrão que confirmam uma boa aderência aos dados.

Tabela 5 - Teste não paramétrico de Wilcoxon para os indicadores

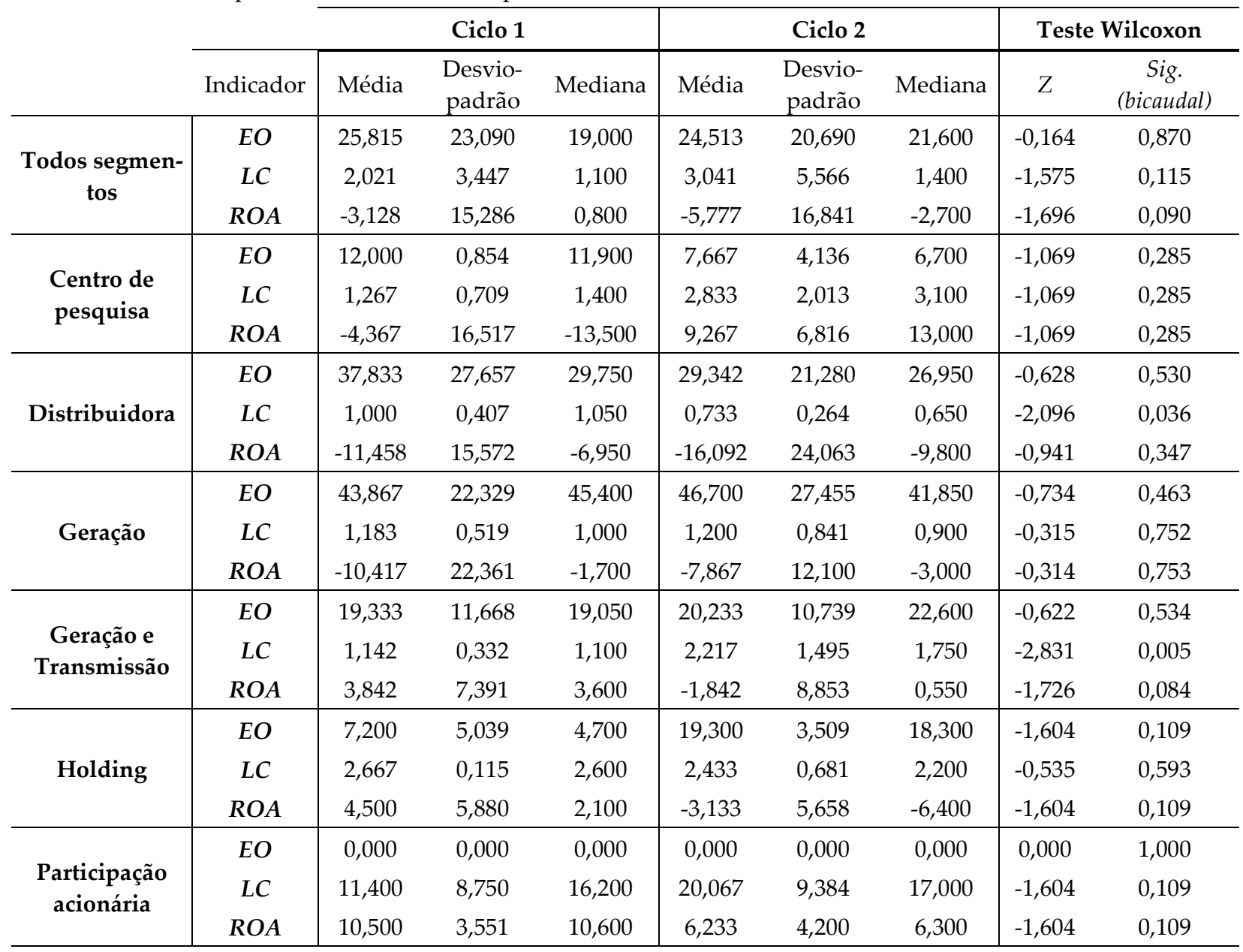

Z - Estatística do teste de Wilcoxon; Sig. (bicaudal) - Significância estatística (p-valor).

$\mathrm{EO}=$ Endividamento Oneroso. $\mathrm{LC}=$ Liquidez Corrente. ROA $=$ Retorno sobre o Ativo Total.

Como o Indicador (EO) mede a participação de empréstimos, financiamentos e arrendamentos mercantis em relação ao total do passivo, no período em análise, pode-se observar que a média, de todos os segmentos do Grupo Eletrobrás, foi maior no ciclo 1 (25,815\%). Cabe destacar, Geração, Geração e Transmissão, e, a Holding, que apresentaram aumento do endividamento no ciclo 2, quando comparado com o ciclo 1. Como sua interpretação consiste em quanto menor melhor o desempenho, pode-se constatar, exceto no segmento Participação Acionária que não apresentou (EO), que no ciclo 1 a menor média foi da Holding (7,2\%) e no ciclo 2 foi do Centro de Pesquisa $(7,667 \%)$.

Ao analisar o indicador (LC) que mensura a capacidade de pagamento no curto prazo, interpretado em quanto maior melhor, pode-se observar que a média de todos os segmentos do 
Grupo Eletrobrás, foi maior no ciclo 2 (3,041). Destacam-se: Distribuidora e Geração e Transmissão, que apresentaram diminuição (LC) no ciclo 2, quando comparado com o ciclo 1. E, a Participação Acionária apresentou maior indicador em ambos os ciclos.

$\mathrm{O}$ (ROA) que mede a rentabilidade das operações da empresa em relação aos seus ativos médios, pode ser interpretado no desempenho da empresa em quanto maior melhor. Nos resultados apresentados observa-se que a média de todos os segmentos do Grupo Eletrobrás, foi maior negativamente no ciclo 2 (-5,777\%). Destaca-se a Participação Acionária que apresentou maior (ROA) no ciclo 1 (10,5\%), e, no ciclo 2 o Centro de Pesquisa $(9,267 \%)$.

Assim, a partir desse cenário, conforme Tabela 5, ao nível de significância de 5\% (bicaudal), há indícios que existe diferença estatisticamente significativa entre os ciclos político-orçamentários, apenas para o indicador (LC) nos segmentos: Distribuidora (p-valor 0,036) e Geração e Transmissão (p-valor 0,005).

Contudo, para os outros segmentos, não há diferença dos indicadores econômicofinanceiros analisados nos dois ciclos políticos, revelando um cenário negativo para o setor elétrico estatal, no qual o nível de endividamento é elevado, a liquidez corrente é baixa e o retorno esperado do ativo em sua maioria é negativo.

O fato dos demais indicadores não apresentarem estatisticamente diferenças entres os ciclos 1 e 2, mesmo sendo os dois ciclos da mesma base partidária, mas com características de ineficiência administrativa externada pelos resultados, sinaliza traços de personalização do poder. Como são reflexos da gestão dos DAN, que por sua vez são vinculados a elite dirigente que os contemplou com os cargos de DAS 5 e 6, acaba por corroborar com aspectos do patrimonialismo de Weber (2000) que destaca por consistir em uma relação de dominação, onde somente acontece caso os homens dominados se submetam à autoridade continuamente reivindicada pelos dominadores.

Para D’Araújo (2014) no Brasil, os temas politização da máquina pública e incompetência na administração pública estatal vem à tona na imprensa e no debate acadêmico, por suspeita de clientelismo, partidarismo e corporativismo, impactando a boa governança.

Em seguida, a Tabela 6 apresenta os resultados o Teste de Wilcoxon aplicado para verificar se existe diferença estatística entre a vinculação político-partidária dos Dirigentes de Alto Nível (DAN) da Diretoria Executiva do Grupo Eletrobrás por segmentos e por ciclos políticoorçamentários. Cabe destacar, que no período em análise, foram identificados quatrocentos e trinta e três (433) DAN, dos quais cento e trinta e três (133) como Dirigentes Filiados (DF) e cento e oitenta e cinco (185) como Dirigentes Doadores.

Ao constatar que tanto os DF quanto os DD apresentam vinculação político-partidária, obtém-se $68 \%$ de DAN com vinculação político-partidária. Os segmentos de Distribuidora (191) e Geração e Transmissão (135) se destacam por possuírem os maiores números de DAN, sendo o segmento Geração e Transmissão o de maior número de DF (61), bem como o de maiores doadores para partidos políticos (64) e, ainda, que se candidataram em eleições (20). 
Tabela 6 - Teste não paramétrico de Wilcoxon para a vinculação político-partidária dos DAN

\begin{tabular}{|c|c|c|c|c|c|c|c|c|}
\hline & \multicolumn{3}{|c|}{ Ciclo 1} & \multicolumn{3}{|c|}{ Ciclo 2} & \multicolumn{2}{|c|}{ Teste Wilcoxon } \\
\hline & Média & $\begin{array}{l}\text { Desvio- } \\
\text { padrão }\end{array}$ & Mediana & Média & $\begin{array}{l}\text { Desvio- } \\
\text { padrão }\end{array}$ & Mediana & Z & Sig. (bicaudal) \\
\hline Total & 34,000 & 54,364 & 11,000 & 41,133 & 71,794 & 7,000 & $-0,561$ & 0,575 \\
\hline Centro de pesquisa & 15,000 & 1,800 & 0,000 & 2,000 & 4,140 & 0,000 & $-1,732$ & 0,083 \\
\hline Distribuidora & 9,200 & 21,102 & 1,000 & 11,467 & 27,573 & 1,000 & $-0,898$ & 0,369 \\
\hline Geração & 6,333 & 9,155 & 0,000 & 7,600 & 11,636 & 0,000 & $-1,633$ & 0,102 \\
\hline Geração e Transmissão & 12,733 & 16,956 & 5,000 & 14,267 & 22,099 & 2,000 & $-0,446$ & 0,655 \\
\hline Holding & 3,533 & 5,527 & 1,000 & 5,267 & 8,472 & 1,000 & $-2,041$ & 0,041 \\
\hline Participação acionária & 0,400 & 1,549 & 0,000 & 0,533 & 2,066 & 0,000 & $-1,000$ & 0,317 \\
\hline
\end{tabular}

Z - Estatística do teste de Wilcoxon; Sig. (bicaudal) - Significância estatística (p-valor).

DAN = Dirigentes de Alto Nível.

Ao nível de significância de 5\% (bicaudal) apenas o segmento Holding (p-valor 0,041) apresentou indícios que existe diferença estatisticamente significativa entre os ciclos políticoorçamentários, no que se refere a vinculação político-partidária dos DAN por segmentos do Grupo Eletrobrás.

Esse poder político que era a base que dominava a máquina política e administrativa do país, fazem derivar seus benefícios de poder e prestígio, em termos weberianos, revelam um patrimonialismo estamental, que Faoro defendia no Brasil, ou seja, uma forma de dominação política tradicional típica de sistemas centralizados.

A contribuição de Faoro aqui vai além da utilização dos conceitos weberianos e da interpretação que deu do sistema político brasileiro, consiste, principalmente, em chamar a atenção sobre a necessidade de reexaminar o sistema político nele mesmo. Para Matias-Pereira (2013), percebe-se o retorno de características do patrimonialismo na administração pública, evidenciadas pelos principais casos de corrupção no país, além da influência burocrática, cujos excessos contribuem para ineficiência na performance do Estado.

\subsection{ANÁLISE DE CLUSTER}

Com o intuito de identificar dento das características analisadas pelas variáveis desse estudo, quais segmentos possuíram maiores similaridades dentro do Grupo Eletrobrás, a Análise de Cluster gerou os dendrogramas apresentados nas Figuras de 2 a 6, pelo Método Aglomerativo Hierárquico, com nível de similaridade pela métrica distância euclidiana e pelo método de ligação simples, ou seja, mínima distância ou vizinho mais próximo (Mingoti, 2005). 


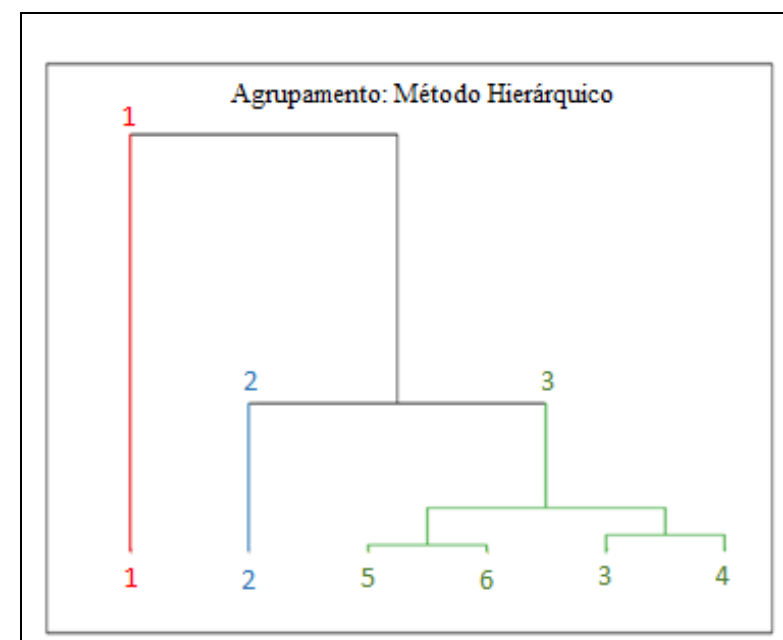

FIGURA 2 - Dendograma dos Orçamentos de Custeio e Investimentos por segmentos do Grupo Eletrobrás

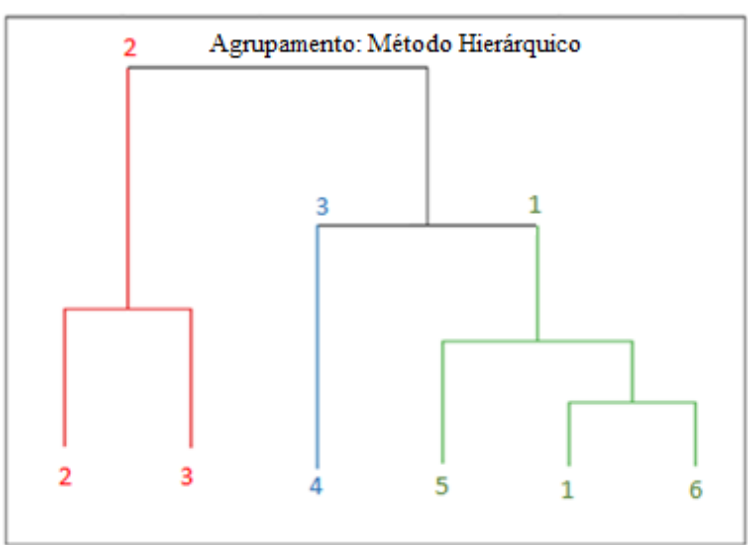

FIGURA 4 - Dendograma da vinculação políticopartidária dos DAN por segmentos do Grupo Eletrobrás



FIGURA 3 - Dendograma dos Indicadores Financeiros por segmentos do Grupo Eletrobrás

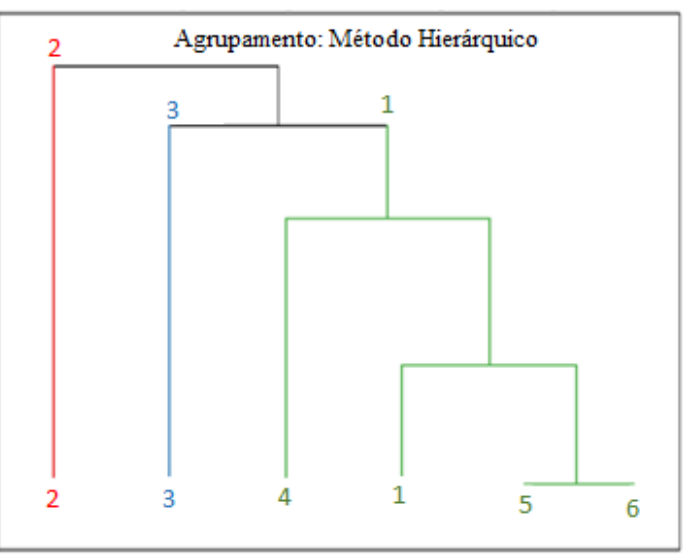

FIGURA 5 - Dendograma dos dirigentes filiados por segmentos do Grupo Eletrobrás



FIGURA 6 - Dendograma dos dirigentes doadores por segmentos do Grupo Eletrobrás

Figura 7 - Dendogramas

Nota. Holding (1), Geração e Transmissão (2), Geração (3), Distribuidora (4), Participação Acionária (5) e Centro de Pesquisa (6).

Por se tratar de uma análise confirmatória, na figura 2 observa-se no cluster (1) apenas pelo segmento Holding (1), no cluster (2) o segmento Geração e Transmissão (2) e no cluster (3) os demais 
segmentos Geração (3), Distribuidora (4), Participação Acionária (5) e Centro de Pesquisa (6), ou seja, é a estrutura de distribuição do volume de recursos públicos que são destinados ao Grupo Eletrobrás pelos orçamentos de investimentos.

Na figura 3, observa-se no primeiro cluster os segmentos dos códigos 1, 2 e 6 (Holding, Geração e Transmissão e Centro de Pesquisa), no segundo cluster os de códigos 3 e 4 (Geração e Distribuidoras) e no terceiro cluster encontra-se apenas o código 5 (Participação Acionária). Dessa forma, foram formados os grandes grupos por similaridade em relação aos indicadores econômicofinanceiros, destacando o cluster 2 por tratar dos segmentos de pior desempenho.

Tenório \& Saravia (2006) defendem que a ineficiência do aparelho burocrático brasileiro não será resolvida por meios de modernizações, reformas ou de adjetivações, mas sim pela redefinição da importância da administração pública como vetor necessário ao desenvolvimento nacional e à equitativa redistribuição social e regional da renda.

As figuras 4, 5 e 6, correspondem à análise da vinculação político-partidária dos DAN, onde no geral, o maior número de filiados a partidos políticos e o maior número de doares foram identificados como vinculados ao Partido dos Trabalhadores (PT). Destaca-se, o segmento Centro de Pesquisa que, apesar de não possuir DF efetuou doações e o segmento Geração e Transmissão por ter sido o que mais doou em eleições para o PT.

$\mathrm{Na}$ figura 4, a similaridade no primeiro cluster foi formada pelos segmentos 1, 6 e 5 (Holding, Participação Acionária e Centro de Pesquisa), no segundo cluster pelos segmentos 2 e 3 (Geração e Transmissão e Geração) e no terceiro cluster apenas pelo segmento 4 (Distribuidoras). Na figura 5, o primeiro cluster foi composto pelos segmentos 1, 5, 6 e 4 (Holding, Participação Acionária, Centro de Pesquisa e Distribuidoras), o segundo cluster pelo segmento 2 (Geração e Transmissão), e, o terceiro cluster pelo segmento 3 (Geração). E, na figura 6, o primeiro cluster agrupou os segmentos 1, 4, 5 e 6 (Holding, Distribuidoras, Participação Acionária e Centro de Pesquisa), sendo o segundo cluster formado pelo segmento 2 (Geração e Transmissão) e o terceiro pelo segmento 3 (Geração).

Quanto à vinculação político-partidária dos DAN, no âmbito do grupo Eletrobrás, pode-se observar que os segmentos: Holding (1), Participação Acionária (5) e Centro de Pesquisa (6) são semelhantes nos três aspectos verificados, vinculação política, filiação partidária e doação a partidos políticos.

O fato de $68 \%$ de DAN possuírem vinculação político-partidária, sendo desses a maioria filiados e doares ao Partido dos Trabalhadores (PT), que é a base dos dois ciclos políticos analisados, apontam características do patrimonialismo weberiano que Costa (2012) caracteriza no quadro administrativo, como sendo composto por companheiros ou súditos, recrutados por critérios de afetividade, lealdade. Para Bilhim (2013), nas quatro últimas décadas, assistiu-se a uma crítica generalizada ao desempenho organizações públicas, acusadas de fidelidade ao modelo weberiano e, consequentemente, de estarem em contraciclo com a evolução social, impondo-se, por isso, a modernização administrativa.

Portanto, progredindo com a lógica desse pensamento, acredita-se que na busca pelo poder do Estado, esse cenário faz parte do jogo político. Ao atuarem com tomadas de decisão que envolvem os interesses da sociedade, em seus mais amplos aspectos, preservar "vantagens próprias", evidenciando a cultura patrimonialista, ao tratar o interesse público no segundo plano, não é mais uma filosofia aceitável na administração pública brasileira.

\section{CONSIDERAÇÕES FINAIS}

Após comparados os ciclos políticos por segmentos do Grupo Eletrobrás em relação ao desempenho dos indicadores econômico-financeiros, de 2008 a 2014, revelaram um cenário negativo, com nível de endividamento elevado, liquidez corrente baixa e retorno esperado do ativo negativo, 
em sua maioria e com existência de diferença estatisticamente significativa apenas para o indicador de desempenho Liquidez Corrente nos segmentos: Distribuidora e Geração e Transmissão.

No que diz respeito a análise da vinculação político partidária dos DAN, permitiu-se identificar um quadro final com sustentação teórica, no qual $68 \%$ dos dirigentes possuem vinculações político-partidárias com a base do governo do poder executivo, nos ciclos analisados.

Ao longo dos dois ciclos, foi mantida as características de ineficiência administrativa externada pelos resultados dos indicadores econômico-financeiros analisados, sinalizando traços de personalização do poder, que em conjunto com o elevado percentual de vinculação política, acaba por corroborar com o que Weber $(2000,2002)$ destaca como traços de patrimonialismo, ao estabelecer uma relação de dominação, onde os critérios de lealdade são mantidos e comprometem o desempenho das organizações públicas.

Nesse sentido, pela apresentação literária e exploração do setor elétrico estatal, o Estado tem sido impelido a reconfigurar-se. Como os elementos analisados contribuem para levantar a discussão sobre a existência de vinculações políticas em rede, esse achado, torna inadiável uma reflexão sobre a presença do patrimonialismo em estatais, que acabam por alavancar mazelas políticas existentes nos espaços institucionais de domínio público.

A temática explorada gera questionamentos que sustentam diversas discussões, entre elas, a necessidade de identificar o modelo em que a Administração Pública brasileira melhor se enquadra, em refletir sobre aspectos que impeçam avanços na área, em busca de uma compreensão mais densa sobre o principal achado da pesquisa. Logo, espera-se que este trabalho possa motivar a realização de pesquisas futuras, ampliando o campo de discussão sobre o tema e refazendo o percurso trilhado em outros setores estatais.

\section{REFERÊNCIAS}

Agência Nacional de Energia Elétrica. (2018). Informações sobre o modelo brasileiro de geração de energia elétrica. Recuperado em de: http://www.aneel.gov.br/.

Aras, G., \& Crowther, D. (2009). Corporate sustainability reporting: a study in disingenuity? Journal of Business Ethics, n. 87, n. 1, p. 279-288, 2009.

Assaf Neto, A. (2012). Estrutura e análise de balanços: um enfoque econômico-financeiro. 10. ed. São Paulo: Atlas.

Baldwin, R., \& CAVE, M. (1999). Understanding regulation: theory, strategy and practice. New York: Oxford University, 1999.

Basso, L. F. C., \& Silva, M. R. (2000). Reflexões sobre a regulamentação. Revista de Administração Contemporânea, Curitiba, v. 4, n. 2, p. 67-85, 2000.

Bilhim, J. (2013). Papel dos gestores na mudança cultural da administração central do estado: o caso da meritocracia. Passagens. Revista Internacional de História Política e Cultura Jurídica, 5(2), 205-227, 2013.

Boyer, R. A. (1990). Teoria da Regulação: Uma análise Crítica. São Paulo: Nobel, 1990.

Brasil. Constituição da República Federativa de 1988. Diário Oficial da República Federativa do Brasil. Brasília, no 191-A, de 05 de outubro de 1988. Recuperado de: http://www.planalto.gov.br/ccivil_03/constituicao/ConstituicaoCompilado.htm. 
Brasil. Decreto $n^{\underline{0}}$ 6.944, de 21 de agosto de 2009. Estabelece medidas organizacionais para o aprimoramento da administração pública federal direta, autárquica e fundacional, dispõe sobre normas gerais relativas a concursos públicos, organiza sob a forma de sistema as atividades de organização e inovação institucional do Governo Federal, e dá outras providências. Recuperado de: http://www.planalto.gov.br/ccivil_03/_ato2007-2010/2009/decreto/d6944.htm.

Brasil. Decreto nº 8.886, de 24 de outubro de 2016. Aprova a Estrutura Regimental e o Quadro Demonstrativo dos Cargos em Comissão e das Funções de Confiança da Comissão Nacional de Energia Nuclear - CNEN, remaneja cargos em comissão e substitui cargos em comissão do Grupo Direção e Assessoramento Superiores - DAS por Funções Comissionadas do Poder Executivo - FCPE. Recuperado de: http://www.planalto.gov.br/ccivil_03/_ato20152018/2016/decreto/D8886.htm.

Brasil. Decreto Lei nº 200, de 25 de fevereiro de 1967. Dispõe sobre a organização da Administração Federal, estabelece diretrizes para a Reforma Administrativa e dá outras providências. Recuperado de: https://www.planalto.gov.br/ccivil_03/Decreto-Lei/Del0200.htm.

Brasil. Lei no 13.303, de 30 de junho de 2016. Dispõe sobre o estatuto jurídico da empresa pública, da sociedade de economia mista e de suas subsidiárias, no âmbito da União, dos Estados, do Distrito Federal e dos Municípios. Recuperado de: http://www.planalto.gov.br/ccivil_03/_ato2015-2018/2016/lei/113303.htm.

Brasil. Medida Provisória $n^{\circ} 579$ de setembro de 2012. Dispõe sobre as concessões de geração, transmissão e distribuição de energia elétrica, sobre a redução dos encargos setoriais, sobre a modicidade tarifária e dá outras providências. Recuperado de: http://www.planalto.gov.br/ccivil_03/_ato2011-2014/2012/Mpv/579.htm.

Brasil. Lei $n^{\circ} 12.783$, de 11 de janeiro de 2013. Dispõe sobre as concessões de geração, transmissão e distribuição de energia elétrica, sobre a redução dos encargos setoriais e sobre a modicidade tarifária; altera as Leis nos 10.438, de 26 de abril de 2002, 12.111, de 9 de dezembro de 2009, 9.648, de 27 de maio de 1998, 9.427, de 26 de dezembro de 1996, e 10.848, de 15 de março de 2004; revoga dispositivo da Lei no 8.631, de 4 de março de 1993; e dá outras providências. Recuperado de: http://www.planalto.gov.br/ccivil_03/_ato20112014/2013/Lei/L12783.htm.

Campante, R. G. (2003), "O Patrimonialismo em Faoro e Weber e a Sociologia Brasileira". DADOS, vol. 46, nº1, pp. 153-193.

Campbell, A. (1997). Stakeholders: the case in favour. Long Range Planning, v. 30, n. 3, p. 446-449, 1997.

Carvalho, J. M. (1980). A Construção da Ordem - A Elite Política Imperial. Rio de Janeiro, Campus.

Carvalho, C. J. (2009). O recrutamento ministerial em 20 anos de democracia no Brasil (1985-2005). Lisboa: Edições Colibri, 2009. (Estudos da FCSH-UNL, n. 23).

Corrêa, V. L. A. (2010). Perfil de los ocupantes de cargos de confianza del ejecutivo federal brasileño: una comparación entre el gobierno de FHC y de Lula (1996 a 2006). Revista ADM.MADE, 14(3), 28-46. 
Costa, G. P. (2012). Heranças patrimonialistas, (dis)funções burocráticas, práticas gerenciais e os novos arranjos do Estado em rede: entendendo a configuração atual da administração pública brasileira. 253 f. Tese (doutorado) - Escola Brasileira de Administração Pública e de empresas, Centro de Formação Acadêmica e Pesquisa, Fundação Getúlio Vargas, Rio de Janeiro.

D’Araújo, M. C. (2009). A elite dirigente do governo Lula. Rio de Janeiro, FGV/CPDOC.

D’Araújo, M. C. (2014). Redemocratização e mudança social no Brasil. Rio de Janeiro: Editora FGV.

Departamento de Coordenação e Governança das Empresas Estatais. (2017). Disponibilização das informações econômico-financeiras das empresas estatais. Recuperado de: https://gerta.dest.planejamento.gov.br/gerta/public/pages/acessoPublico.jsf.

Centrais Elétricas Brasileiras S.A. (2017). Informações sobre o Grupo Eletrobrás. Recuperado em 05 de outubro, 2017, de: http://www.eletrobras.com/.

Franco, M. S. C. (1976). As idéias estão no lugar. Cadernos de Debates, n.1. São Paulo: Brasiliense, 1976.

Fávero, L. P. L., Belfiore, P. P., Silva, F. L., \& Chan, B. L. (2009). Análise de dados - modelagem multivariada para tomada de decisões. Rio de Janeiro: Campus/Elsevier.

Faoro, R. (1979). Os donos do poder. 3 ed. Editora Globo.

Faoro, R. (2001). Os donos do poder: formação do patronato político brasileiro. 3. ed. rev. São Paulo: Globo.

Faoro, R. (2012). Os donos do poder: formação do patronato político brasileiro. 5 ed. São Paulo: Globo.

Garrison, R. H., Noreen, E. W. \& Brewer, P. C. (2013). Contabilidade gerencial. 14ª Ed. McGraw-Hill.

Gitman, L. J. (2010). Princípios de administração financeira. 12. ed. São Paulo: Pearson Prentice Hall.

Holanda, S. B. (1976). Raízes do Brasil. 9. ed. Rio de Janeiro: José Olympio, 1976.

Holanda. S. B. (1995). Raízes do Brasil. 26ª ed. São Paulo: Companhia das Letras, 1995.

Inácio, M. (2013). Escogiendo Ministros y Formando Politicos: los partidos en gabinetes multipartidistas. América Latina Hoy, v. 64.

Janert, P. K. (2011). Data Analysis with Open Source Tools. 1 ed. O'Reilly.

Portela Jr., A. (2012). Florestan Fernandes e o conceito de patrimonialismo na compreensão do Brasil. Revista do Programa de Pós-Graduação em Sociologia da USP, v. 19, n. 2, p. 9-27.

Kaplan, R. S., \& Norton, D. P. (1997). A estratégia em ação: Balanced Scorecard. 10.ed. Rio de Janeiro: Campus, 1997.

Lamounier, B. (2014). Tribunos, profetas, sacerdotes. Intelectuais e ideologias no século XX. São Paulo: Cia das Letras. 
Majone, G. (1999). Do Estado positivo ao Estado regulador: causas e consequências de mudança no modo de governança. Revista do Serviço Público, v. 50, n. 1, p. 5-36, 1999.

Malhotra, N. K. (2001). Pesquisa de Marketing: uma orientação aplicada. 3. ed. Porto Alegre: Bookman.

Maroco, J. (2007). Análise Estatística com a utilização do SPSS. 3. ed. Silabo. Lisboa.

Matias-Pereira, J. (2013). The effects of the recovery of the patrimonialist model in Brazil. International Journal of Humanities and Social Science, v. 3, n. 8, p. 27-38.

Manly, B. J. F. (2008). Métodos Estatísticos Multivariados: uma Introdução. Porto Alegre: Artmed.

Mingoti, S. A. (2005). Análise de dados através de métodos de estatística multivariada: uma abordagem aplicada. Belo Horizonte: Editora UFMG.

Montone, J. (2000). A regulamentação do setor de saúde suplementar. Rio de Janeiro: ANS.

Nava, M. A. R. (2009). Análisis financiero: una herramienta clave para una gestión financeira eficiente. Revista Venezolana de Gerencia, Maracaibo, v. 14, n. 48, p. 606-628.

Olivieri, C. (2007). Política, burocracia e redes sociais: as nomeações para o alto escalão do Banco Central do Brasil. Revista Sociologia e Política, Curitiba, n. 29, p. 147-168.

Palonen, K. (2019). Four aspects of politics in Max Weber's Politik als Beruf. Journal of Classical Sociology, 1468795X1985134. doi:10.1177/1468795x19851343.

Palotti, P., \& Cavalvante, P. (2018). Articuladores políticos e dirigentes da burocracia: ministros de Estado no Brasil e em perspectiva comparada. In: PIRES, R.; LOTTA, G. S.; OLIVEIRA, V. E. (Orgs.). Burocracia e políticas públicas no Brasil: interseções analíticas. Brasília: Ipea; Enap, 2018. cap. 6.

Possas, M. L., Pondé, J. L., \& Fagundes, J. (1997). Regulação da concorrência nos setores de infraestrutura no Brasil: elementos para um quadro conceitual. Rio de Janeiro: Instituto de Economia da UFRJ, 1997. Recuperado de:

$<$ http://www.ie.ufrj.br/grc/pdfs/regulacao_da_concorrencia_nos_setores_de_infraestrutura_ no_brasil.pdf>.

Póvoa, A. (2010). Livros de Valor: Valuation, como precificar ações. São Paulo. Editora Globo, 2 ed.

Ramalho, P. I. S. (2009). Regulação e agências reguladoras: reforma regulatória da década de 1990 e desenho instrucional das agências no Brasil. In: Ramalho, Pedro Ivo Sebba (Org.). Regulação e Agências Reguladoras: Governança e Análise de Impacto Regulatório. Brasília: Anvisa, 2009.

Rocha Neto, L. H. (2008). A Formação Do Estado Brasileiro: Patrimonialismo, Burocracia e Corrupção. Revista do Mestrado em Direito da Universidade Católica de Brasília, v. 2, n. 1.

Ross, S. A., Westerfield, R. W., Jordan, B. D., \& Lamb, R. (2013). Fundamentos da Administração Financeira. Editora McGraw-Hill, 9 ed. 
Silva, H. P. (2002/2003). Estado, regulação e saúde: considerações sobre a regulação econômica do mercado de saúde suplementar. Leituras de Economia Política, Campinas, n. 10, p. 193-226, jun. 2002/jun. 2003.

Souto, M. J. V. (1999). Agências Reguladoras. Revista Direito Administrativo, Rio de Janeiro, n. 216, p. 125-162.

Sistema de Informações Estatais. (2017). Relatório perfil das estatais. Recuperado de: https://camweb.dest.planejamento.gov.br/camweb/grupo?sis=PGERTA\&url=gerta.dest.pla nejamento.gov.br\%2Fgerta\%2F.

Tenório, F. G., \& Saravia, E. J. (2006). Escorços sobre gestão pública e gestão social. In: Martins, P. E. M., \& Pieranti, O. P. Estado e Gestão Pública: visões do Brasil Contemporâneo. 2. ed. Rio de Janeiro: FGV, 2006.

Tribunal Superior Eleitoral. (2017). Consulta a filiação partidária. Recuperado em 05 de outubro, 2017, de: http://www.tse.jus.br/partidos/filiacao-partidaria/filiacao-partidaria.

Weber, M. (2000). Economia e Sociedade: fundamentos da sociologia compreensiva. Tradução de Regis Barbosa e Karen Elsabe Barbosa. Brasília: Editora Universidade de Brasília, 2000.

Weber, M. (2002). A ética protestante e o espírito do capitalismo. São Paulo: Editora Martin Claret.

Weber, M. (2004a). Economia e sociedade: fundamentos da sociologia compreensiva. Regis Barbosa e Karen Elsabe Barbosa (Trad.). v.1. Brasília-DF: Editora da Universidade de Brasília.

Weber, M. (2004b). Economia e Sociedade: fundamentos da sociologia compreensiva. Regis Barbosa 